\title{
Different Capabilities of Morphological Pattern Formation and Its Association with the Expression of Differentiation Markers in a Xenograft Model of Human Pancreatic Cancer Cell Lines
}

\author{
Daniel Neureiter ${ }^{a, c}$ Steffen Zopf ${ }^{b}$ Arno Dimmler ${ }^{a}$ Sebastian Stintzing ${ }^{b}$ \\ Eckhart G. Hahn ${ }^{\mathrm{b}}$ Thomas Kirchner $^{\mathrm{a}}$ Christoph Herold $^{\mathrm{b}}$ Matthias Ocker $^{\mathrm{b}}$ \\ Departments of a Pathology and ${ }^{\mathrm{b}}$ Medicine I, Friedrich Alexander University Erlangen-Nürnberg, \\ Erlangen, Germany and ${ }^{\mathrm{C}}$ Institute of Pathology, Landeskliniken Salzburg, Salzburg, Austria
}

\section{Key Words}

Pancreatic carcinoma cell lines Xenografts ·

Transitions states $\cdot$ Transdifferentiation .

Dedifferentiation

\begin{abstract}
Aims: New concepts of tumorigenesis favor an unregulated process recapitulating different stages of embryogenic development with dysregulation of transition states. The aim of our study was to investigate the possibility of differentiation pathways of human pancreatic cancer cell lines in vivo. Material and Methods: Different human pancreatic cancer cell lines (YAPC, DAN-G, CAPAN-1, PANC-1 and MIA PaCa-2) were implanted subcutaneously $\left(3 \times 10^{6}\right.$ cells) for 28 days in nude mice. Xenotransplants were characterized with histochemistry (HE, PAS), immunohistochemistry (cytokeratin (CK)7, CK8, CK18, CK19, CK20, vimentin, chromogranin A (Chr-A), $\alpha_{1}$-antichymotrypsin ( $\alpha_{1}$-chym), $\beta$-catenin, laminin-5, pancreatic and duodenal homeobox gene 1 (pdx1), sonic hedgehog protein (shh), Patched (ptc)), Western
\end{abstract}

D.N., S.Z. and A.D. contributed equally to this work. blotting and real-time PCR (CK7, CK8, CK20, Chr-A, pdx1, shh, ptc). Results: Depending on three major morphologic phenotypes of tumor cell xenotransplants (ductal (YAPC), ductal/solid (DAN-G, CAPAN-1), solid (PANC-1, MIA PaCa-2)), a decrease of CK7/CK19 was found, accompanied by an increase of CK8/18 and vimentin. Predominantly the CK7-positive ductal phenotype (YAPC and DAN-G) was associated with pdx-1 expression, whereas the CK8-positive solid phenotype was associated with shh/ptc expression on protein and mRNA level. Additionally, CK-20 expression was mainly linked to the ductal phenotype, co-localized with nuclear $\beta$-catenin. The endocrine-exocrine transdifferentiation, as assessed by Chr-A and $\alpha_{1}$-chym, was on a constant low to moderate level in all xenotransplants. Finally, an intensive epithelial-mesenchymal interaction was observed by overexpression of laminin-5 at the invasion front. Conclusion: The observed patterns of morphology and molecular differentiation in human pancreatic cancer xenografts indicate that these cancer cell lines have different capabilities of pattern formation in vivo associated with molecular differentiation markers, especially of embryonic pancreatic development.

Copyright $\Subset 2005$ S. Karger AG, Basel and IAP

D. Neureiter, MD

Institute of Pathology, Salzburger Landeskliniken

Paracelsus Private Medical University, Müllnerstrasse 48, A-5020 Salzburg (Austria)

Tel. +43662 4482 4737, Fax +436624482 882

E-Mail d.neureiter@salk.at 


\section{Introduction}

Pancreatic carcinoma is among the most aggressive solid malignancies, being the fifth leading cause of cancer death in the Western world. Despite its rising incidence, little progress has been made in overall survival [1].

The pancreas contains three different cell types: duct cells, exocrine cells and endocrine cells. Transition states of ductal and endocrine cells were observed during embryonic development [2]. Similar phenomena reflecting these processes have been described during tumorigenesis of the pancreas [3].

Newer concepts postulated that differentiation pathways, especially dedifferentation, recapitulating early stages of tissue morphogenesis and cell differentiation during pancreas ontogeny [4-6], are key events in the initiation of tumorigenesis [7, 8]. This hypothesis is supported by the observation of re-expression of genes regulating embryonic pancreas development like sonic hedgehog pathway protein (shh) and its receptor Patched (ptc) $[9,10]$ as well as the pancreatic and duodenal homeobox gene $1(p d x-1)[11,12]$ in pancreatic adenocarcinoma and its precursor lesions of pancreatic intraepithelial neoplasia (PANINA). In part, dedifferentiation was detected by analyzing cytokeratin (CK) expression [13, 14].

Phenomena of transdifferentiation that are associated with phenotype switches (e.g. from exocrine to ductal [15, $16]$, exocrine to endocrine $[17,18]$ as well as from exocrine to mesenchymal $[19,20]$ and vice versa) are reported in pancreas tumorigenesis and reparation as well as in cell culture experiments. For the phenotype switches in transdifferentiation, it is postulated that cells must transiently dedifferentiate to a stem-cell-like phenotype linking de- and transdifferentiation pathways [21]. This is supported by the observation that transdifferentiation is linked with expression of the pancreatic duodenal homeobox-containing transcription factor pdx-1 [19, 2224]. Furthermore, the process of trans- and dedifferentiation might be influenced by interactions with the environment, especially by laminins or $\beta$-catenin, which are important mediators of epithelial-mesenchymal transitions and cell-cell adhesion as well as survival [25-29].

Although these phenomena are specified and have in part been investigated in vitro [20,30], systematical analyses using a xenograft model of human pancreatic cancer cells lines are still rare.

Therefore, the aim of our study was to investigate the possibility of differentiation pathways of human pancreatic cancer cell lines in vivo by a phenotype analysis using various specific markers of differentiation.

\section{Material and Methods}

\section{Cell Culture}

YAPC, DAN-G, CAPAN-1, PANC-1 and MIA PaCa-2 pancreatic adenocarcinoma cells were cultured in RPMI-1640 medium (Biochrom, Berlin, Germany) containing 10\% fetal bovine serum (Biochrom), penicillin $\left(10^{7} \mathrm{U} / 1\right.$, Biochrom) and streptomycin (10 mg/l, Biochrom) at $37^{\circ} \mathrm{C}$ and $5 \% \mathrm{CO}_{2}$. YAPC, DAN-G and CAPAN-1 were obtained from the German Collection of Microorganisms and Cell Cultures (DSMZ, Braunschweig, Germany) and PANC-1 and MIA PaCa-2 from the ATCC (Manassas, Va., USA), respectively.

In vitro Analysis

For in vitro assays, 150,000 cells were seeded per well of a 6-well culture plate (BD Biosciences, Heidelberg, Germany) or on chamber slides (Nunc, Wiesbaden, Germany) until confluence.

\section{Xenograft Model}

Pancreatic carcinoma cell lines were harvested and resuspended in sterile physiologic $\mathrm{NaCl}$ solution. $3 \times 10^{6}$ cells were injected subcutaneously into the flank of 4- to 6-week-old male NMRI mice (Harlan Winkelmann GmbH, Borchen, Germany). For each cell line, 5 animals were used. Animals were kept in a light- and temperature-controlled environment and provided with food and water ad libitum. Tumor size was determined daily by measurement with a caliper square. After 28 days, animals were sacrificed by cervical dislocation and specimens of tumor were either fixed in $10 \%$ phosphate-buffered formalin or snap-frozen in liquid nitrogen. Ethical approval was achieved before the beginning of experiments.

Phenotypic Characterization of Pancreatic Cancer Cell Lines and Xenograft Specimens

Total protein was extracted from snap-frozen tumor samples, pooled from all animals of one group and subjected to SDS-PAGE as described previously [31]. Membranes were probed with the antibodies given in table 1 . Reactive bands were detected with the ECL chemiluminescence reagent (Amersham Pharmacia Biotech, Freiburg, Germany), digitized on a LAS-1000 luminescence image analyzer (Fuji Photo Film, Düsseldorf, Germany) and analyzed using GelScan 5 software (BioSciTec, Frankfurt, Germany).

Fixed and paraffin-embedded tumor sections were subjected to routine hematoxylin and eosin (HE) staining and PAS reaction. Immunohistochemistry (IHC) was performed on pancreatic cancer cells xenografts as described [31]. Samples were analyzed with the antibodies given in table 1 . HE staining was used to evaluate basic histomorphology of the specimens, especially ductal and solid morphology which was assigned if the tumor displayed ductal and solid formations in $>75 \%$ of the whole specimen. The epithelial mucopolysaccharides were detected by the PAS reaction.

To evaluate the extension of the IHC, the slides with the immunohistochemistical stainings were divided in quarters, digitized completely and analyzed quantitatively (\% positive area) with the Ce2001 Cell Explorer software (BioSciTec). The intensity of the IHC staining was evaluated semiquantitatively $(-=$ negative; ()$=$ focally positive; $+=$ weakly positive; $++=$ positive $;+++=$ strongly positive). 
Table 1. Primary antibodies and antigen retrieval methods used for immunohistochemical analysis

\begin{tabular}{lllll}
\hline Antigen specificity & Type & Dilution & $\begin{array}{l}\text { Antigen } \\
\text { retrieval }\end{array}$ & Vendor \\
\hline CK7 & Mouse monoclonal & $1: 1,000$ & $\mathrm{P}$ & BioGenex \\
CK8 & Mouse monoclonal & $1: 200$ & $\mathrm{MW}$ & BioGenex \\
CK18 & Mouse monoclonal & $1: 1,000$ & $\mathrm{P}$ & Sigma \\
CK19 & Mouse monoclonal & $1: 500$ & $\mathrm{P}$ & DakoCytomation \\
CK20 & Mouse monoclonal & $1: 50$ & $\mathrm{MW}$ & DakoCytomation \\
Vimentin & Mouse monoclonal & $1: 200$ & $\mathrm{MW}$ & DakoCytomation \\
Chr-A & Mouse monoclonal & $1: 1,000$ & $\mathrm{MW}$ & DakoCytomation \\
$\alpha_{1}$-chym & Rabbit polyclonal & $1: 10,000$ & $\mathrm{P}$ & Sigma \\
Laminin 5 (laminin $\left.\gamma_{2}\right)$ & Mouse monoclonal & $1: 30$ & Pt & Chemicon \\
$\beta$-Catenin & Rabbit polyclonal & $1: 100$ & $\mathrm{MW}, \mathrm{TRS}$ & Sigma \\
Mib-1 & Mouse monoclonal & $1: 100$ & $\mathrm{MW}$ & DakoCytomation \\
pdx-1 & Rabbit polyclonal & $1: 250$ & MW & Chemicon \\
shh & Goat polyclonal & $1: 100$ & MW & SantaCruz \\
ptc & Goat polyclonal & $1: 50$ & MW, TRS & SantaCruz \\
\hline
\end{tabular}

$\mathrm{P}=$ Pronase $\left(2 \mathrm{mg} / \mathrm{ml}, \mathrm{PBS}, \mathrm{pH} 7.4,10 \mathrm{~min}\right.$ at $37^{\circ} \mathrm{C}$; Sigma, Germany $) ; \mathrm{Pt}=$ protease $\mathrm{XXIV}(0.05 \mathrm{mg} / \mathrm{ml}, \mathrm{PBS}$, $\mathrm{pH} 7.2,10 \mathrm{~min}$ at $37^{\circ} \mathrm{C}$; Sigma, Germany $)$, MW = microwave $(10 \mathrm{mmol} / 1$ citrate buffer, $\mathrm{pH} 6.0 ; 10 \mathrm{~min}$ at $800 \mathrm{~W}$ and $10 \mathrm{~min}$ at $560 \mathrm{~W})$; TRS = target retrieval solution $(\mathrm{pH}$ 6.0; DakoCytomation, Denmark) used instead of citrate buffer.

\section{RNA Isolation and Reverse Transcription}

Total cellular RNA was extracted by use of the RNeasy Kit in combination with DNAse treatment (Qiagen, Hilden, Germany), as described in the manual. The RNA was eluted in $30 \mu$ l of RNAsefree water. RNAs were pooled from all animals of one group. Firststrand cDNA was synthesized using Superscript II RNAse H-Reverse Transcriptase (Life Technologies, Karlsruhe, Germany). $4 \mu 1$ of RNA elute were added to $1 \mu \mathrm{g}$ of dT15 primers (TIB-Biomol, Berlin, Germany) and $1 \mu M$ random hexamers (Promega, Heidelberg, Germany). After annealing for $10 \mathrm{~min}$ at $70^{\circ} \mathrm{C}$ and immediate cooling on ice, $1 \times$ first strand buffer (Life Technologies), $10 \mathrm{mM}$ DTT (Life Technologies), $0.5 \mu$ l enzyme (100 units) and $0.5 \mathrm{mM}$ deoxynucleotide triphosphate (Carl Roth, Karlsruhe, Germany) were added to get a total reaction volume of $10 \mu \mathrm{l}$. The reaction was allowed to proceed for $50 \mathrm{~min}$ at $42^{\circ} \mathrm{C}$, followed by $15 \mathrm{~min}$ at $70^{\circ} \mathrm{C}$ to inactivate the enzyme. After cDNA synthesis, distilled water was added to achieve a final volume of $100 \mu \mathrm{l}$ in each sample.

\section{Quantitative Real-Time PCR}

Primers were designed by use of the Primer Express software, Version 2.0.0 (Perkin-Ellmer Applied Biosystems, Foster City, Calif., USA). The sequences of primers are listed in table 2. Each PCR assay was repeated three times for each cDNA sample. The $25 \mu \mathrm{l}$ total PCR volume consisted of $5 \mu \mathrm{l}$ cDNA, $12.5 \mu$ l SYBRGreen PCR Master Mix (Applied Biosystems, Martinsried, Germany) and primers (MWG-Biotech, Ebersberg, Germany) in the following concentrations: $800 \mathrm{n} M$ each for GAPDH and $400 \mathrm{n} M$ each for the residual genes. After denaturation and activation of the hotstart enzyme for $10 \mathrm{~min}$ at $95^{\circ} \mathrm{C}$, the PCR assays were carried out for 40 cycles, with denaturation at $95^{\circ} \mathrm{C}$ for $15 \mathrm{~s}$, annealing and extension at $60^{\circ} \mathrm{C}$ for $1 \mathrm{~min}$. To monitor amplification of pos- sible contaminated DNA, distilled water served as a negative control.

Fluorometric PCR was performed with the ABI Prism 7700 Sequence Detection System (Perkin-Elmer Applied Biosystems). After target amplification, SYBRGreen specifically binds to doublestranded DNA, which leads to an increase in detectable fluorescence signals. The amount of product detectable through fluorescence signals at any given cycle within the exponential phase of PCR is proportional to the initial number of template copies. The number of PCR cycles needed to detect the amplicon is therefore a direct measure of the template concentration. Threshold cycle was set when emission intensity of measurable fluorescence calibrated to starting level became equal to 10 standard deviations of the baseline.

Absolute quantification was achieved through generation of standard curves using serial dilutions of known concentrations of the different cDNAs. The RT-PCR results were expressed as the ratio of molecules of target gene (e.g. CK7) per 1,000 molecules of housekeeping gene (GAPDH) normalized to the mean expression level of all five cell lines. To monitor amplification of genomic DNA due to pseudogenes, RNA aliquots without reverse transcription were always amplified as negative controls.

Melting curve analysis was performed after each PCR run. After denaturation at $95^{\circ} \mathrm{C}$ for $20 \mathrm{~s}$, a temperature ramp from 60 to $95^{\circ} \mathrm{C}$ in 20 min was run with simultaneous acquisition of fluorescence signals. At the melting point of double-stranded PCR products, an accelerated decline of fluorescence can be recognized. Using negative first-deviation plots, we checked each sample for primer dimers and unspecific products due to mispriming. 
Table 2. Sequences of human primers used for real-time PCR experiments

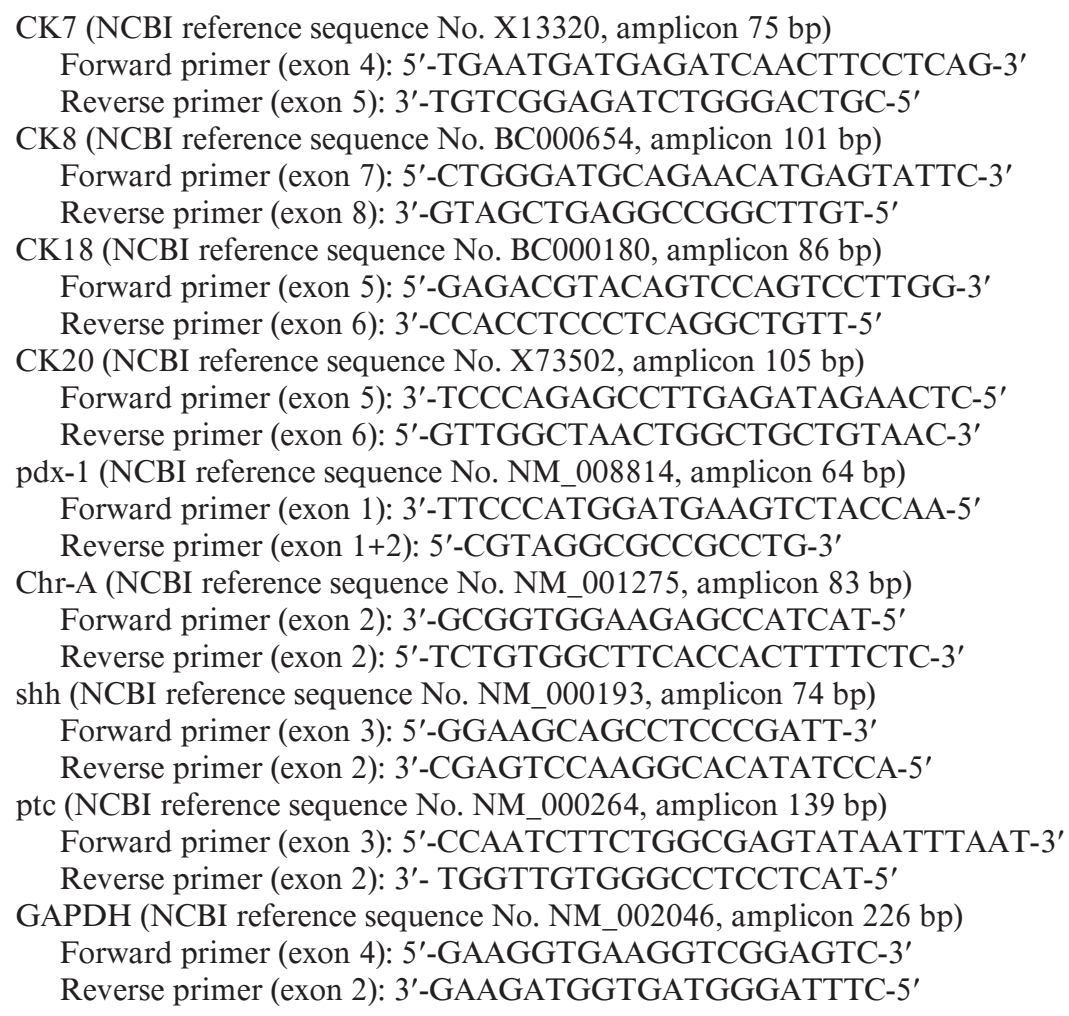

Furthermore, agarose gel electrophoresis of selected samples out of each PCR run was performed to check for unspecific amplification products.

\section{Results}

\section{Human Pancreatic Cancer Cell Line Xenografts in vivo}

The tumor implants showed a continuous growth in all cases measured by planimetry. The mean tumor volume $( \pm \mathrm{SD})$ after 28 days as well as the Mib-1 proliferation rate (\%) was (in increasing order): CAPAN-1 (364 $\pm 148 \mathrm{~mm}^{3}$; 75\%), PANC-1 (990 $\left.\pm 530 \mathrm{~mm}^{3} ; 80 \%\right)$, YAPC (1,089 \pm $\left.740 \mathrm{~mm}^{3} ; 80 \%\right)$, MIA PaCa-2 (1,143 $\left.\pm 1,290 \mathrm{~mm}^{3} ; 85 \%\right)$ and DAN-G (1,963 $\left.\pm 235 \mathrm{~mm}^{3} ; 90 \%\right)$.

\section{Morphology (see table 3, fig. 1)}

Besides transitional areas, three different morphological growth patterns of the human pancreatic cancer cell lines were found in the xenografts: YAPC showed predominantly typical duct like structures with cuboid tu- mor cells, DAN-G and CAPAN-1 formed a mix of ductal and solid structures, while PANC-1 and MIA PaCa-2 showed solid tumor formations with different tumor cell morphology (cuboid and focally sarcomatoid). The nuclear polymorphology increased with the loss of ductal differentiation which was associated with the loss of PASpositive mucopolysaccharides.

Immunophenotype of Xenografts (see table 3, fig. 1)

CK7/CK19 and CK8/CK18 Profile. The expression of typical pancreatic CKs (CK7/CK19 and CK8/CK18) and of the typical mesenchymal marker vimentin correlated with histological pattern and tumor grading. Typical ductal structures showed a strong expression of CK7/CK19, which was decreased in solid tumor formations, whereas CK8/CK18 was increased, accompanied by an increased expression of vimentin. Overall a clear zonal distribution of these CKs could not be observed. CK7/CK19 and CK8/CK18 were mainly found in the periphery of DAN-G and PANC-1 xenografts. An association between tumor cell morphology and expression of CK7/CK19 as well as CK8/CK18 could not be established. 
Table 3. Immunohistochemical quantification of typical trans- and dedifferentiation patterns of subcutaneous human pancreatic cancer cell line xenografts in nude mice

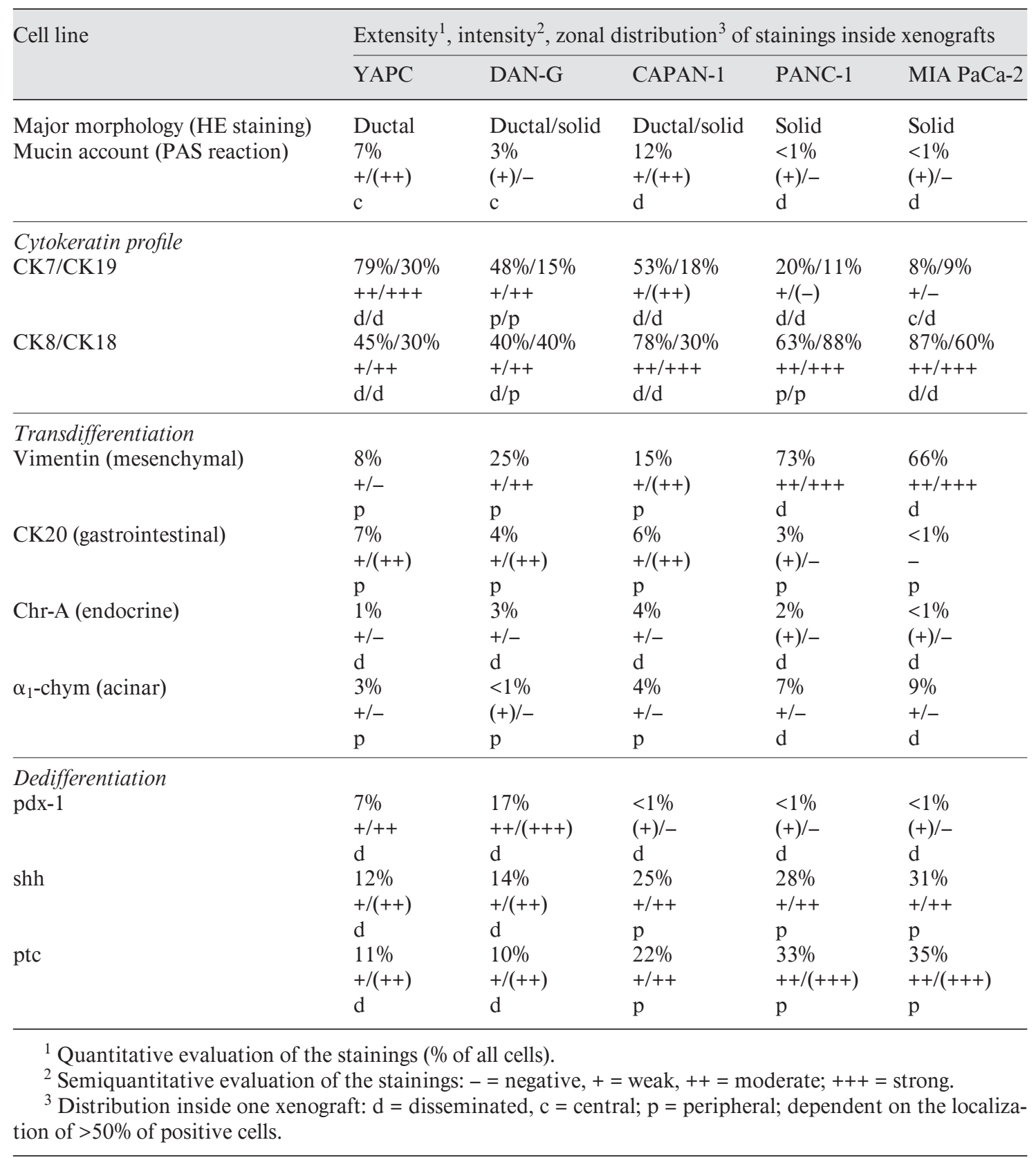

Expression of Transdifferentiation Markers. CK20 expression was mainly found in tumor xenografts with ductal differentiation (YAPC) or mixed ductal and solid structures (DAN-G and CAPAN-1). In these cases a predominant peripheral location of CK20 expression was found and was associated with a tubulus-like phenotype of ductal tumor formation (CAPAN-1) which mimicked PANINA.

$\beta$-Catenin was diffusely localized at the cytoplasm membrane in the xenografts of YAPC, DAN-G and CAPAN-1. Focally, a nuclear expression of $\beta$-catenin, colocalized with the expression of CK20, was also observed 


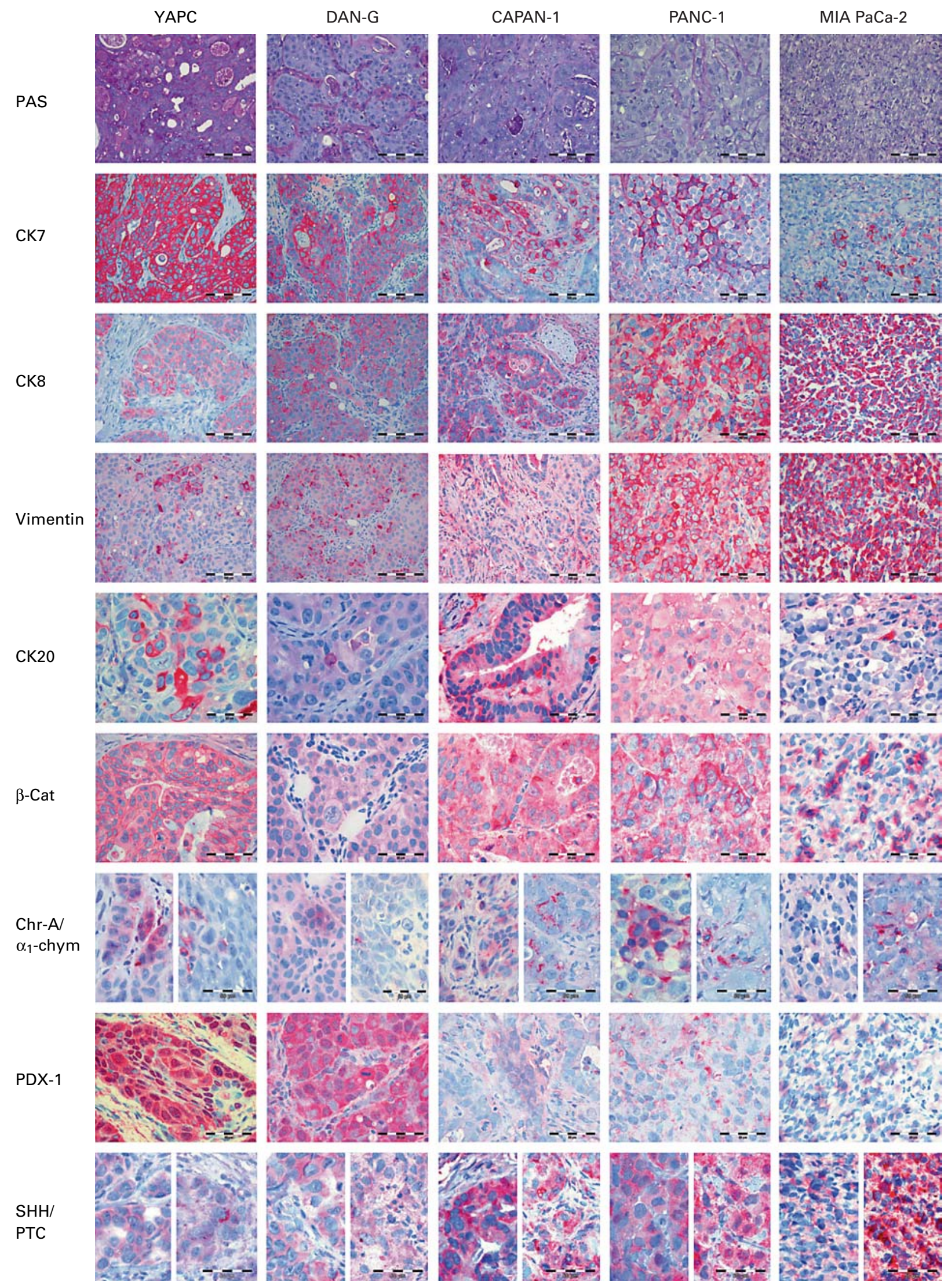




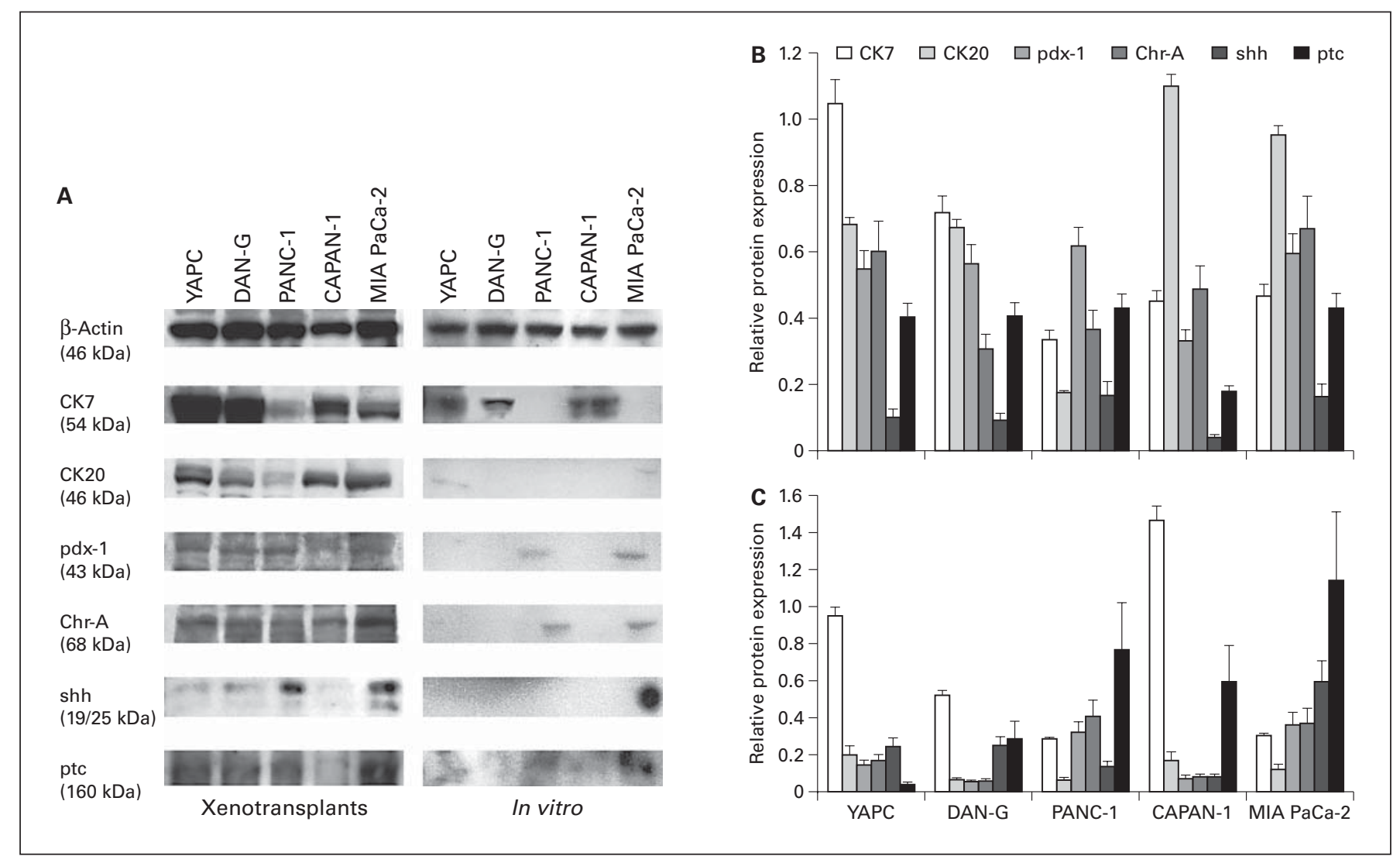

Fig. 2. Western blot analysis of CK7, CK20, Chr-A, pdx-1, shh and ptc in different human pancreatic cancer cells in vitro and in xenotransplants. Shown are representative examples of Western blotting from pooled total protein of 5 xenografts per cell line and the naïve cell lines $(\mathbf{A})$. The bar diagrams show the mean densitometric analysis of two independent Western blots $( \pm$ SEM) in xenotransplants $(\mathbf{B})$ and in vitro $(\mathbf{C})$.

in CAPAN-1. An obviously enhanced cytoplasmic expression of $\beta$-catenin in combination with a loss of membranous staining was found in human pancreatic cancer cell lines PANC-1 and MIA PaCa-2 in the periphery of the xenografts.

Chromogranin A (Chr-A), being a marker for endocrine differentiation, was detected mainly in solid areas of tumor samples. Yet, expression was observed only in disseminated cells with a low overall expression level. The expression of $\alpha_{1}$-antichymotrypsin ( $\alpha_{1}$-chym), which was used as a marker for acinar differentiation, increased

Fig. 1. Typical morphological and expression pattern of trans- and dedifferentiation inside pancreatic tumor cell line implants in nude mice as determined by immunohistochemistry (magnification: PAS until vimentin: $20 \times$ objective (bar $100 \mu \mathrm{m}$ ) and CK20 until shh: $40 \times$ objective $($ bar $50 \mu \mathrm{m})$ ).

Morphogenesis and Transition States of Pancreatic Cancer Cell Xenografts from low in YAPC, DAN-G and CAPAN-1 xenografts (1-4\% of all cells) to moderate in PANC-1 and MIA PaCa-2 (7-9\% of all cells). Finally, a laminin-5 overexpression was observed at the tumor invasion front in all cancer cell lines (data not shown).

Expression of Dedifferentiation Markers. Interestingly, pdx-1 was exclusively expressed in differentiated ductal tumor formations of YAPC and DAN-G cancer cell lines while shh and ptc were linked to CAPAN-1, PANC-1 and MIA PaCa-2. Similar to CK expression, no association between tumor cell morphology and expression of pdx-1, shh and ptc could be established.

\section{Western Blot Analysis and $m R N A$ Analysis of}

Xenografts (see fig. 2A, B, 3A)

Overall, the Western blot and mRNA analyses confirmed the immunohistochemical findings. Although all human cancer cell lines expressed CK7, the highest levels 


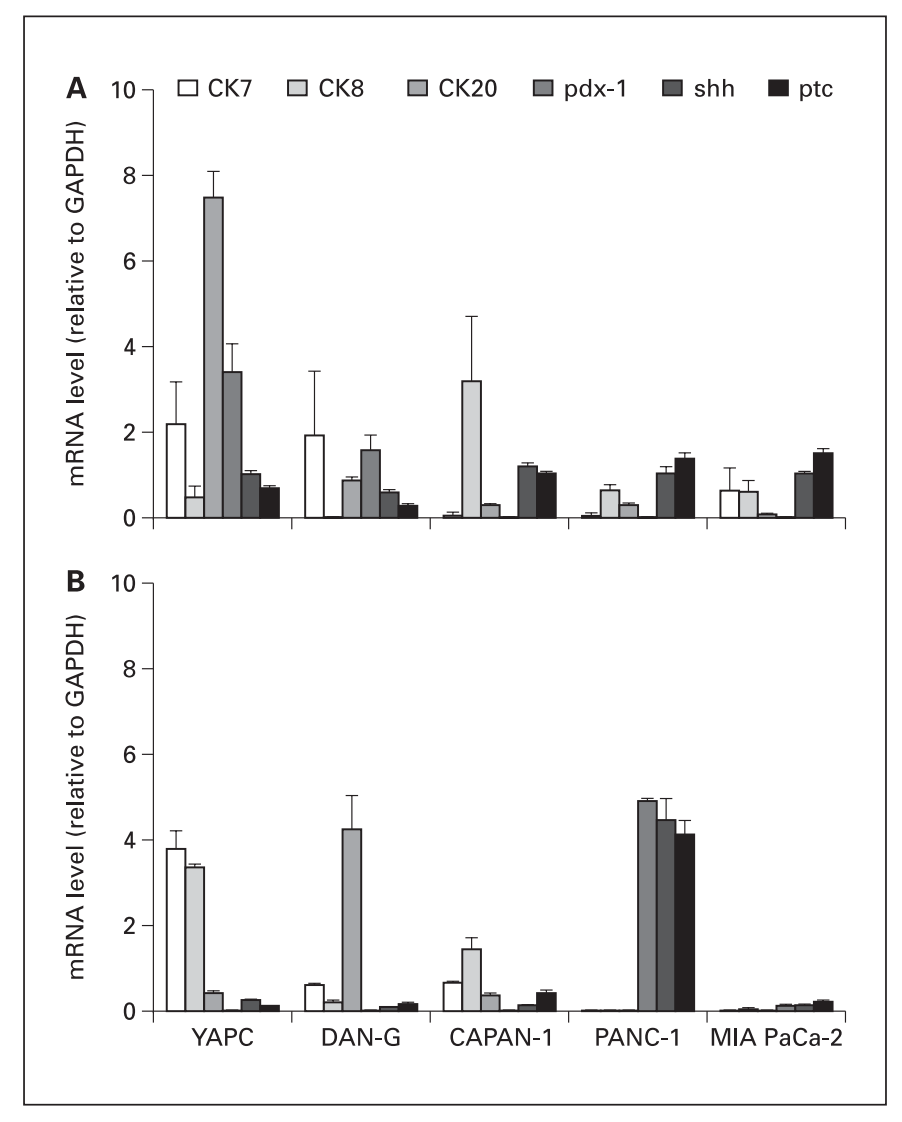

Fig. 3. Quantitative real-time PCR of CK7, CK8, CK20, pdx-1, shh and ptc mRNA of different human pancreatic cancer cells in vivo (A) and in vitro (B). Shown are mean mRNA levels of two independent experiments ( \pm SEM), expressed relative to the level of GAPDH mRNA.

of protein and mRNA were found in tumors with a ductal or ductal/solid phenotype. Comparable to the IHC results, the loss of morphologic differentiation was associated with increased levels of CK8. The expression levels of CK 7 and CK8 were associated with the mRNA levels of dedifferentiation parameters: In cases with high amount of pdx-1 (YAPC and DAN-G) higher levels of CK7 and lower levels of CK8 and shh/ptc than in all other cancer cell lines were detected. Protein and mRNA levels of CK20 were associated with pdx-1 and CK7-expression. Finally, low levels of Chr-A protein were detectable in DAN-G, PANC-1 and CAPAN-1 while MIA PaCa-2 showed high levels of Chr-A mRNA (data not shown) and protein.

\section{Human Pancreatic Cancer Cell Lines in vitro}

(see fig. 2A, C, 3B)

Pancreatic carcinoma cell lines express the classical ductal human pancreatic cancer CK pattern profile (CK7/ CK19 and/or CK8/CK18) in vitro as proven by immunocytochemistry (data not shown), Western blotting and mRNA analysis. In detail, expression of CK7 in combination with CK8 was found in YAPC, DAN-G and CAPAN-1, whereas CK8 was only detected in PANC-1 and MIA PaCa-2 pancreatic cancer cell lines. Expression of markers of trans- and dedifferentiation (Chr-A, pdx-1 and ptc) was only marginally detectable in PANC-1 and MIA PaCa-2 cell lines. Expression of CK20 (determined by Western blot and mRNA analysis) was only faintly seen in YAPC. Interestingly, these results were not paralleled for DAN-G and PANC-1 on mRNA levels regarding CK20 and shh.

\section{Comparison of Protein and $m R N A$ Expression in vitro and in vivo}

The typical CK profile of human pancreas could be detected in vitro and in vivo. In contrast to in vitro experiments, PANC-1 and MIA PaCa-2 show a novel expression of $\mathrm{CK} 7$, a marker of ductal differentiation, in vivo.

Although focal expression of markers of trans- and dedifferentiation could already be observed in vitro. These phenomena were more enhanced on protein level in all human pancreatic cancer cell line xenografts, especially for CK20 (YAPC, DAN-G, CAPAN-1, MIA PaCa-2), Chr-A (all), pdx-1 (YAPC, DAN-G, PANC-1), shh (PANC-1 and MIA PaCa-2) and ptc (all except CAPAN1). Although single genes were overexpressed in vivo (e.g. CK20 in YAPC, pdx-1 in YAPC and DAN-G, shh and ptc in MIA PaCa-2), the overall expression pattern of mRNA was heterogeneous between in vitro and in vivo experiments.

\section{Discussion}

In this model of human pancreatic carcinoma xenografts in nude mice, we demonstrated that different human ductal pancreatic carcinoma cell lines exhibit distinct morphological patterns and molecular markers of trans- and dedifferentiation. In detail, we detected two major specialized morphologic and molecular pathways 
inside different human ductal pancreatic carcinoma cell lines: (i) a ductal tumor pattern (YAPC and DAN-G) with predominance of $\mathrm{CK} 7$ and pdx-1 and (ii) a more dedifferentiated solid tumor pattern (CAPAN-1, MIA PaCa-2 and PANC-1) with increased expression of CK8 and shh/ ptc. These findings are of special interest as they indicate that xenografts of human pancreatic tumor cell lines have the potency to express markers known in embryonic pancreatic development, showing that these cell lines can reactivate otherwise inactive signaling pathways of development.

Embryologic development of the pancreas is under control of several homeodomain box proteins [for detailed reviews, see 4-6]: Among these, members of the sonic hedgehog protein family (shh) and their cognate receptors, Patched (ptc), are involved in pancreatic morphogenesis, regulating the formation of the dorsal and ventral endodermal buds with later fusion [32-34]. Additionally, ductal and endocrine differentiations arise from exocrine parts of the embryonic pancreas and are controlled by the pancreas duodenum homeodomain protein pdx-1, which is expressed in the whole pancreas in early embryonic development but is only found in $\beta$-cells of endocrine islets in the adult pancreas $[35,36]$. Additionally, shh and pdx-1 are also upregulated in pancreatic tumorigenesis $[9,12]$, while the functional significance of this is so far unknown. There is some evidence that shh and pdx-1 act contrary in some circumstances (amniote embryo) [37], while we and others observed synergistic regulation of shh and $\mathrm{pdx}-1$ on the protein level in mature pancreas (at least in mammals) [38] and in zebrafish embryo [39]. Ductal alterations preceding carcinoma formation, so-called PANINA, are spatiotemporally regulated by differential expression of shh [10] and pdx-1 [11]. In concordance with our observations, recent investigations on epithelial intermediate filament proteins demonstrated that dedifferentiation is associated with different expression of CKs [13, 14].

Interestingly, we found that these factors of embryologic development (pdx-1 and shh/ptc) as well as the CK profile are associated with morphological signs and protein expression patterns of transdifferentiation. A tubular transdifferentiation with enhanced expression of CK20 was observed in the ductal group [40, 41]. This was associated with an increased expression of $\beta$-catenin in well-differentiated human carcinoma cell lines. Additionally, we confirmed the findings of Joo et al. [28] and Qiao et al. [29] that grading of pancreas cancer is associated with reduced membranous and cytoplasmatic expression of $\beta$-catenin. Expression of vimentin, a classical marker of mesenchymal differentiation, was mainly observed in dedifferentiated human carcinoma cell lines like MIA $\mathrm{PaCa}-2$, which corroborates earlier findings $[13,20]$. Furthermore, the vimentin-positive cell lines PANC-1 and MIA PaCa-2 showed a reduced expression of pdx-1 and elevated levels of ptc which is in line with the current literature [19]. These cell lines also displayed a higher expression of $\alpha_{1}$-chym indicating a true acinar transdifferentiation. Endocrine transdifferentiation was observed at low levels in all human pancreas carcinoma cell lines, indicating that this is not limited to the known pdx-1 ductal pathway [22, 23].

In particular, expression of molecular markers of transand dedifferentiation were more pronounced in a physiologic environment compared to cell culture conditions.

The observed overexpression of laminin-5 at the tumor border confirmed that epithelial-mesenchymal interactions are essentially involved in the tumor progression, also in pancreatic cancer [26].

Overall, growing evidence suggests that tumorigenesis repeats embryologic development pathways in many aspects: Neoplastic cells re- or dedifferentiate into a stemcell-like phenotype with the potential of proliferation [25, 27]. One of the best examples in this field is the adenocarcinoma of the colon. Intensive morphologic analyses of colon tumors showed that tumor formation imitates typical morphological patterns of budding and branching during embryogenesis which was confirmed by molecular analyses [42]. Additional studies of gastric carcinomas showed that neoplastic changes in the gastric cancer sequence are associated with dedifferentiation imitating fetal morphogenesis [43], indicating that these mechanisms are commonly found in gastrointestinal tumor development and might also apply to pancreatic carcinogenesis.

According to our study design, we are aware that this is a relatively static glance at the differentiation potential of the various human pancreatic cancer cell lines in a nude mouse xenograft model, regardless of immediate changes after xenografting due to technical reasons (injection of tumor cell suspension).

In summary, the observed findings indicate that (i) human pancreatic cancer cell lines have the complete potential for differentiation in vivo, (ii) imitating different stages of embryonic pancreatic development, (iii) which could possibly be used further as a tool for designing specific tumor therapies. 


\section{Acknowledgements}

We are indebted to Claudia Knoll, Gisela Weber, Christa Winkelmann, Sandra Leitner and Andrea Hartl for excellent technical assistance and to Gabriele Krumholz for support in animal care and animal experiments. We thank Dr. Susanne Müerköster, Divi- sion of Molecular Gastroenterology and Hepatology, 1st Department of Medicine, University Kiel, Germany, for her valuable support.

Supported by the German Cancer Aid (10-2112-Oc1) and the ELAN Programme of the Faculty of Medicine, University of Erlangen-Nürnberg (Project 03.08.01.1).

\section{References}

1 Bardeesy N, DePinho RA: Pancreatic cancer biology and genetics. Nat Rev Cancer 2002;2: 897-909.

2 Slack JM: Developmental biology of the pancreas. Development 1995;121:1569-1580.

3 Bouwens L: Cytokeratins and cell differentiation in the pancreas. J Pathol 1998;184:234239.

4 Wilson ME, Scheel D, German MS: Gene expression cascades in pancreatic development. Mech Dev 2003; 120:65-80.

$5 \mathrm{Gu}$ G, Brown JR, Melton DA: Direct lineage tracing reveals the ontogeny of pancreatic cell fates during mouse embryogenesis. Mech Dev 2003; 120:35-43.

6 Hebrok M: Hedgehog signaling in pancreas development. Mech Dev 2003;120:45-57.

7 Wicking C, Smyth I, Bale A: The hedgehog signalling pathway in tumorigenesis and development. Oncogene 1999;18:7844-7851.

8 Johansson KA, Grapin-Botton A: Development and diseases of the pancreas. Clin Genet 2002;62:14-23.

9 Berman DM, Karhadkar SS, Maitra A, Montes DO, Gerstenblith MR, Briggs K, Parker AR, Shimada Y, Eshleman JR, Watkins DN, Beachy PA: Widespread requirement for hedgehog ligand stimulation in growth of digestive tract tumours. Nature 2003;425:846851 .

10 Thayer SP, Di Magliano MP, Heiser PW, Nielsen CM, Roberts DJ, Lauwers GY, Qi YP, Gysin S, Fernandez-Del Castillo C, Yajnik V, Antoniu B, McMahon M, Warshaw AL, Hebrok M: Hedgehog is an early and late mediator of pancreatic cancer tumorigenesis. Nature 2003;425:851-856.

11 Song SY, Gannon M, Washington MK, Scoggins CR, Meszoely IM, Goldenring JR, Marino CR, Sandgren EP, Coffey RJ Jr, Wright CV, Leach SD: Expansion of Pdx1-expressing pancreatic epithelium and islet neogenesis in transgenic mice overexpressing transforming growth factor- $\alpha$. Gastroenterology 1999;117: 1416-1426.

12 Koizumi M, Doi R, Toyoda E, Masui T, Tulachan SS, Kawaguchi Y, Fujimoto K, Gittes GK, Imamura M: Increased PDX-1 expression is associated with outcome in patients with pancreatic cancer. Surgery 2003;134:260266.
13 Schussler MH, Skoudy A, Ramaekers F, Real FX: Intermediate filaments as differentiation markers of normal pancreas and pancreas cancer. Am J Pathol 1992;140:559-568.

14 Gershengorn MC, Hardikar AA, Wei C, GerasRaaka E, Marcus-Samuels B, Raaka BM: Epithelial-to-mesenchymal transition generates proliferative human islet precursor cells. Science 2004; 306:2261-2264.

15 Lardon J, Huyens N, Rooman I, Bouwens L: Exocrine cell transdifferentiation in dexamethasone-treated rat pancreas. Virchows Arch 2004; 444:61-65

16 Tokoro T, Tezel E, Nagasaka T, Kaneko T, Nakao A: Differentiation of acinar cells into acinoductular cells in regenerating rat pancreas. Pancreatology 2003;3:487-496.

17 Rooman I, Lardon J, Bouwens L: Gastrin stimulates $\beta$-cell neogenesis and increases islet mass from transdifferentiated but not from normal exocrine pancreas tissue. Diabetes 2002;51:686-690.

18 Bouwens L: Transdifferentiation versus stem cell hypothesis for the regeneration of islet $\beta$ cells in the pancreas. Microsc Res Tech 1998 43:332-336.

19 Ko SH, Suh SH, Kim BJ, Ahn YB, Song KH, Yoo SJ, Son HS, Cha BY, Lee KW, Son HY, Kang SK, Bonner-Weir S, Weir GC, Yoon KH, Park CG: Expression of the intermediate filament vimentin in proliferating duct cells as a marker of pancreatic precursor cells. Pancreas 2004;28:121-128.

20 Schmied BM, Ulrich A, Matsuzaki H, Ding X Ricordi C, Weide L, Moyer MP, Batra SK, Adrian TE, Pour PM: Transdifferentiation of human islet cells in a long-term culture. Pancreas 2001;23:157-171.

21 Eguchi G, Kodama R: Transdifferentiation. Curr Opin Cell Biol 1993;5:1023-1028.

22 Hosotani R, Ida J, Kogire M, Fujimoto K, Doi $\mathrm{R}$, Imamura M: Expression of pancreatic duodenal hoemobox-1 in pancreatic islet neogenesis after surgical wrapping in rats. Surgery 2004; 135:297-306.

23 Rooman I, Heremans Y, Heimberg H, Bouwens L: Modulation of rat pancreatic acinoductal transdifferentiation and expression of PDX-1 in vitro. Diabetologia 2000;43:907914.
24 Sharma A, Zangen DH, Reitz P, Taneja M, Lissauer ME, Miller CP, Weir GC, Habener JF, Bonner-Weir S: The homeodomain protein IDX-1 increases after an early burst of proliferation during pancreatic regeneration. Diabetes 1999;48:507-513.

25 Kang Y, Massague J: Epithelial-mesenchymal transitions: Twist in development and metastasis. Cell 2004; 118:277-279.

26 Takahashi S, Hasebe T, Oda T, Sasaki S, Kinoshita T, Konishi M, Ochiai T, Ochiai A: Cytoplasmic expression of laminin $\gamma_{2}$ chain correlates with postoperative hepatic metastasis and poor prognosis in patients with pancreatic ductal adenocarcinoma. Cancer 2002;94: 1894-1901.

27 Thiery JP: Epithelial-mesenchymal transitions in tumour progression. Nat Rev Cancer 2002; 2:442-454.

28 Joo YE, Rew JS, Park CS, Kim SJ: Expression of E-cadherin, $\alpha$ - and $\beta$-catenins in patients with pancreatic adenocarcinoma. Pancreatology 2002;2:129-137.

29 Qiao Q, Ramadani M, Gansauge S, Gansauge F, Leder G, Beger HG: Reduced membranous and ectopic cytoplasmic expression of $\beta$ catenin correlate with cyclin D1 overexpression and poor prognosis in pancreatic cancer. Int J Cancer 2001;95:194-197.

30 Sipos B, Moser S, Kalthoff H, Torok V, Lohr M, Kloppel G: A comprehensive characterization of pancreatic ductal carcinoma cell lines: Towards the establishment of an in vitro research platform. Virchows Arch 2003;442: 444-452.

31 Neureiter D, Heuschmann P, Stintzing S, Kolominsky-Rabas P, Barbera L, Jung A, Ocker M, Maass M, Faller G, Kirchner T: Detection of Chlamydia pneumoniae but not of $\mathrm{He}$ licobacter pylori in symptomatic atherosclerotic carotids associated with enhanced serum antibodies, inflammation and apoptosis rate. Atherosclerosis 2003;168:153-162.

32 Dilorio PJ, Moss JB, Sbrogna JL, Karlstrom RO, Moss LG: Sonic hedgehog is required early in pancreatic islet development. Dev Biol 2002;244:75-84.

33 Hebrok M, Kim SK, St Jacques B, McMahon AP, Melton DA: Regulation of pancreas development by hedgehog signaling. Development 2000; $127: 4905-4913$ 
34 Apelqvist A, Ahlgren U, Edlund H: Sonic hedgehog directs specialised mesoderm differentiation in the intestine and pancreas. Curr Biol 1997; 7:801-804.

35 Jonsson J, Carlsson L, Edlund T, Edlund H: Insulin-promoter-factor 1 is required for pancreas development in mice. Nature 1994;371: 606-609.

36 Guz Y, Montminy MR, Stein R, Leonard J, Gamer LW, Wright CV, Teitelman G: Expression of murine STF-1, a putative insulin gene transcription factor, in $\beta$-cells of pancreas, duodenal epithelium and pancreatic exocrine and endocrine progenitors during ontogeny. Development 1995;121:11-18.
37 Hebrok M, Kim SK, Melton DA: Notochord repression of endodermal sonic hedgehog permits pancreas development. Genes Dev 1998; 12:1705-1713.

38 Thomas MK, Lee JH, Rastalsky N, Habener JF: Hedgehog signaling regulation of homeodomain protein islet duodenum homeobox-1 expression in pancreatic $\beta$-cells. Endocrinology 2001;142:1033-1040.

39 Roy S, Qiao T, Wolff C, Ingham PW: Hedgehog signaling pathway is essential for pancreas specification in the zebrafish embryo. Curr Biol 2001;11:1358-1363.

40 Bouwens L, Braet F, Heimberg H: Identification of rat pancreatic duct cells by their expression of cytokeratins 7,19 , and 20 in vivo and after isolation and culture. $\mathrm{J}$ Histochem Cytochem 1995;43:245-253.
41 Wildi S, Kleeff J, Maruyama H, Maurer CA, Friess H, Büchler MW, Lander AD, Korc M: Characterization of cytokeratin 20 expression in pancreatic and colorectal cancer. Clin Cancer Res 1999;5:2840-2847.

42 Kirchner T, Brabletz T: Patterning and nuclear $\beta$-catenin expression in the colonic adenomacarcinoma sequence. Analogies with embryonic gastrulation. Am J Pathol 2000;157: 1113-1121.

43 Kirchner T, Muller S, Hattori T, Mukaisyo K, Papadopoulos T, Brabletz T, Jung A: Metaplasia, intraepithelial neoplasia and early cancer of the stomach are related to dedifferentiated epithelial cells defined by cytokeratin-7 expression in gastritis. Virchows Arch 2001;439:512522 . 